\title{
AT THE CUTTING EDGE
}

\section{Dear Reader,}

2014 is a special year for MTZ. 75 years ago, on $1^{\text {st }}$ March 1939, Prosper L'Orange and Heinrich Buschmann published the very first issue in Stuttgart as a FrancoGerman cooperation. In their first editorial, the founders wrote: "Experts will most actively welcome the value creation of a specialist journal on engine technology ... Within its pages, MTZ aims to bring together the entire literature dealing with the science and engineering of combustion engines ... The new magazine will publish valuable work by leading specialists.” In principle, this mission statement still applies today. The subjects of the first issue, such as the performance characteristics of different cylinder volumes, piston designs and friction losses or the combustion process with different fuels and their influence on engine design, are as topical today as they were back then.

This was shown in particular by the meeting of MTZ's Scientific Advisory Board in November, where the dominant issues on the agenda were alternative fuels and fuel qualities, combustion processes, real driving emissions and their impact on the engine as a whole. MTZ will devote itself even more intensively to these subjects in future and will try to elucidate this complex subject area from many different perspectives. In addition, the topic of electric drive systems will have a firm place alongside internal combustion engines and their peripherals.

The automotive industry and powertrain development in particular are in a phase of upheaval. It has become even more important to anticipate future developments and to develop forward-looking solutions. Like the industry, the publish- ing landscape is also changing, and MTZ is, of course, not unaffected by this. In the second half of the year, the print version and the Springer for Professionals news service and database will be joined by electronic versions of MTZ and its sister magazines. This is necessary not only to reflect the changing reading habits of young engineers in particular and the way they access information. The merging of an e-magazine and a knowledge database will also open up far-reaching opportunities for fast and targeted research directly from the article itself.

This closes a circle that not only tightly links tradition and the modern world in a technical way but also expands the journalistic platform in a future-oriented manner without disregarding what is tried and tested. MTZ always was, is and will remain at the cutting edge of technology.

Best regards,

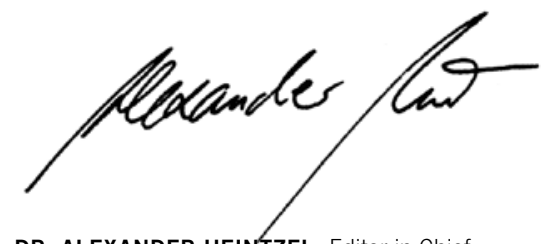

DR. ALEXANDER HEINTZEL, Editor in Chief Wiesbaden, 15 November 2013

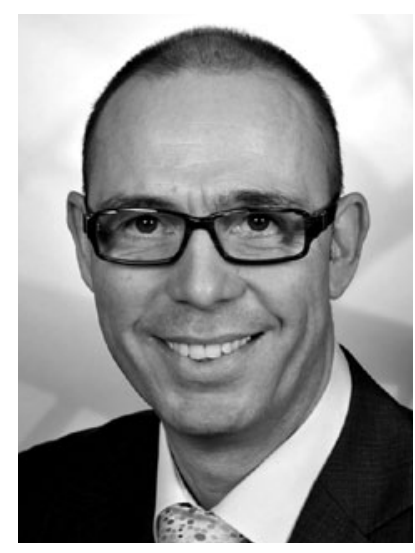

